\title{
DISCOURSE AND COMMUNICATION
}

'Bisexual Oysters': A diachronic corpus-based critical discourse analysis of bisexual representation in The Times between 1957-2017

\section{Mark Wilkinson}

\author{
Version $2-03 / 09 / 18$ \\ Flat 1 - 4E Acre Lane \\ London \\ SW25SG \\ United Kingdom \\ or \\ Linguistics and English Language \\ County South \\ Lancaster University \\ Lancaster \\ LA1 4YL \\ United Kingdom \\ m.wilkinson7@lancaster.ac.uk \\ markj.wilks@gmail.com \\ +4407541490996

\section{'Bisexual Oysters'}

Word count: Six-thousand nine-hundred eighteen

6918

$1.29 \mathrm{MB}$ 


\begin{abstract}
Recent decades have witnessed an increase in LGBTQI visibility in the British media. Increased representation has not been equally distributed, however, as bisexuality remains an obscured sexual identity in discourses of sexuality. Through the use of diachronic corpus-based critical discourse analysis, this study seeks to uncover how bisexual people have been represented in the British press between 1957-2017. By specifically focusing on the discursive construction of bisexuality in The Times, the results reveal how bisexual people are represented as existing primarily in discourses of the past or in fiction. The Times corpus also reveals significant variation in the lexical meaning of bisexual throughout the 60 years in question. These findings contribute to contemporary theories of bisexual erasure which posit that bisexual people are denied the same ontological status as monosexual identities, i.e. homosexuality and heterosexuality.
\end{abstract}

\title{
Keywords:
}

Diachronic corpus-based critical discourse analysis; Discourse analysis; Critical discourse analysis; Corpus-assisted discourse studies; Historical discourse analysis; Discursive construction of identity; Sexual identity; LGBTQI studies; Bisexuality; Bisexual erasure; Media representation; Newspaper discourse; The Times; British Press; Semantic variation; Diachronic variation; Collocation analysis; Concordance analysis; Corpus linguistics; Corpus analysis 


\section{Biography}

I am a PhD candidate at Lancaster University, supervised by Professor Paul Baker. My research is primarily concerned with the discursive construction of sexual identity in the mainstream British media. By using a diachronic approach to corpus-based critical discourse analysis, my work aims to combine historical knowledge with discourse theory in an attempt to map how, when, and why certain identity formations were privileged over others resulting in concepts such as the 'LGBT community' and the de-racialisation of the queer people in popular culture. 


\subsection{Introduction}

Recent decades have witnessed an increase in lesbian, gay, bisexual, transgender, queer, and intersex (LGBTQI) visibility in the British media (Weeks 2016). Increased representation has not been equally distributed, however, as bisexuality continues to remain an obscured sexual identity in contemporary discourses of sexuality. While the meaning of 'bisexual' has changed significantly, bisexual people are contemporarily understood as those who experience sexual/romantic attraction to both male and female identified individuals ${ }^{1}$. Where bisexual people are present in the media, their very existence is challenged as disingenuous, transitional, performative or confused (Yoshino 2000; Angelides 2001; MacDowall 2009; Johnson 2016). This phenomenon is not new. Angelides (2001:1) argues that 'the category of bisexuality for over a century has been persistently refused the title of legitimate sexual identity'. This denial - or bisexual erasure - has become a central theme in contemporary discussions of bisexual identity and how bisexual people and practices have been discursively constructed in the fields of media, politics, law, and health (Yoshino 2000; Worth 2003; Kaestle and Ivory 2012; Johnson 2016). This paper aims to contribute to this area of research by asking how bisexuality was represented in The Times between 1957-2017. By using diachronic corpus-based critical discourse analysis, it is hoped that the discursive construction of bisexual identities over time will reveal the extent to which The Times - as a widely read newspaper in the UK -

\footnotetext{
${ }^{1}$ While gender identity is more complex than simply identifying as a woman or man (Butler 1991), the present article will use the phrase 'male and female identified individuals' when addressing the objects of attraction for bisexual people in the contemporary UK. This binary is likely inadequate in a discussion of sexuality and desire, however, as noted by Yoshino (2001), the very notion of bisexuality reifies the notion that there are two genders.
} 
has either contributed to or challenged the process of bisexual erasure over the past 60 years.

Corpus-based critical discourse analysis is useful in mapping how identity is linguistically represented and constructed. Numerous studies have demonstrated the value of such an approach when looking at sexual identities (Baker 2005) and the representation of marginal identities and minorities in the British Press (Baker et al. 2013). Historical corpora have also been used to examine how groups were represented in the past (McEnery and Baker 2017a, 2017b), revealing the complex ways in which identity is mediated through text as well as the challenges involved in looking at historical language from a contemporary perspective. While diachronic corpus-based critical discourse analysis is not a novel approach, the time periods in question are likely to present two methodological issues that have not been addressed before. First, the 60 years between 1957-2017 yield significantly different quantities of data. This is partly due to the amount of text being published at different times, but also as a result of the increased visibility of sexual minorities in the press. This means that the analysis will have to vary its approaches according to the amount of data available in different decades. Smaller amounts will require more qualitative approaches while larger quantities will be guided by more quantitative corpus approaches. The second issue is concerned with how representative smaller amounts of data can be when considering how bisexual people have been discursively constructed in the British Press. As argued by Fairclough (1989:54), 'a single text on its own is quite insignificant: the effects of media power are cumulative'. It is therefore difficult to claim that bisexual representation in the press had any significant impact on the lived experiences of bisexual people if there are few examples. The 
principal questions for this study concern the effects of discursive representation as well the challenges posed by this particular set of diachronic data:

- How has The Times used language to discursively represent bisexual people between 1957-2017?

- To what extent has The Times contributed to or complicated the notion of bisexual erasure?

- How can qualitative and quantitative methods to corpus analysis be combined when working with different amounts of data in a diachronic corpus?

- To what extent can conclusions be drawn regarding representation when working with smaller amounts of corpus data?

The following literature review will outline some of the key concepts in corpus-based critical discourse analysis used in the present study, followed by a review of bisexual erasure and misrepresentation theories. I will then describe how the corpus was created and which corpus tools were used in the analysis. The results will then be presented in three sections. The first will look at the changing lexical meaning of bisexual/s and bisexuality. The second will discuss representations of bisexuality during the HIV/AIDS crisis and how this era laid the foundations for bisexual erasure and misrepresentation. Finally, I will propose that bisexual people face temporal and fictional displacement in the corpus data which supports and contributes to contemporary discussions of bisexual erasure. The final section will review the findings and consider the methodological questions posed above.

\subsection{Literature Review}

\subsection{Corpus-based critical discourse analysis}


The current study is framed within an analytical tradition that understands discourse as 'practices which systematically form the objects of which they speak' (Foucault 1972: 49). In other words, our knowledge of the social world is largely a product of culturally and historically contingent discourses which are, in part, constituted by language. This is exemplified in our contemporary notions of sexuality. While samesex desire has always existed, the notion of a 'homosexual' or 'bisexual' identity is a product of psychological, medical, and criminal discourses that emerged in Europe during the late $19^{\text {th }}$ century (Foucault 1978). Over time, such ideas were reproduced and mediated through language, eventually becoming accepted as common-sense categories that help people to identify themselves and others. In this way, we can see how bisexuality is not a universal identity across time and space, but rather a discursive construction that emerged in a particular time and location. How and when such a process occurred can be mapped by using diachronic corpus-based critical discourse analysis.

Discourse analysis looks to examples of naturally occurring language for 'traces' of discourse (Fairclough 1989; Van Dijk 1993; Sunderland 2004). Corpus linguistic methods can enhance this analysis by approaching a representative sample of language with computational methods, thereby revealing elements that would not have been visible in a smaller quantity of data. In the present study, I will be focusing on collocation and the close reading of concordance lines as an entry point to how bisexual people have been discursively constructed.

Collocation refers to the frequent co-occurrence of words in a particular corpus (Stubbs 2001). While the frequency of a single word may provide insight into certain aspects of the corpus, the analysis of how words interact with one another can also 'be 
useful in revealing how meaning is acquired through repeated uses of language, as certain concepts become inextricably linked together over time' (Baker 2014:18). In other words, if certain lexical items frequently occur together then the occurrence of a word in isolation may still 'trigger' the connotations and encoded cultural concepts that are produced through its collocate (Stubbs 1996, 2001). For instance, if bisexual frequently occurs near the word promiscuous, then a 'strong' theory of collocation would suggest that bisexual might come to act as a psychological trigger for the idea of promiscuity. This point is of particular significance in the context of how marginal identities are represented in the media. According to Stubbs (1996:92), 'if particular lexical and grammatical choices are regularly made, and if people and things are repeatedly talked about in certain ways, then it is plausible that this will affect how they are thought about'. Frequent collocates may, therefore, affect how bisexual people are represented and how they are perceived.

In addition to collocation, Baker (2010:24) suggests carrying out 'concordancing work in order to identify exactly how the relationship is manifested in language'. For instance, even if bisexual frequently collocates with promiscuous (as in the example above), an analysis of concordance lines may reveal that in many cases the two words appear together because authors are challenging the idea that bisexual people are being represented as promiscuous. Concordance lines may reveal grammatical features that indicate something relevant to representation, e.g. past tense verbs may indicate that bisexual promiscuity is being discussed as something that occurred in the past. Qualitative analysis of discourse, therefore, enhances the data that has been generated through corpus linguistic techniques, enabling a more robust and nuanced analysis of how bisexual people have been represented through language. 
This study combines two approaches to corpus-based critical discourse analysis. On the one hand, I am taking a 'naïve' view when approaching the question of how bisexuality has been represented, allowing the data to guide the analysis (see Partington et al 2013). On the other hand, I also want to interrogate the corpus for 'traces' of bisexual erasure as well as how bisexual people have been misrepresented in the discourse of the British Press. This latter approach is more congruent with critical discourse analysis in which the researcher begins by focusing on a social wrong in its semiotic aspect and then selects for texts in which the problem is 'semiotically realised' (Fairclough, 2010:245). My political position is that media representations of marginal identities and minority communities impact on how such groups are perceived. Uncovering and drawing attention to such inaccurate or negative representations is a critical step in mitigating such discourses and improving the lives of those affected. The following discussion will, therefore, further explore discourses of bisexual erasure and misrepresentation in order to frame how the corpus data will be interpreted.

\subsection{The Erasure and Misrepresentation of Bisexual People}

Contemporary theories of bisexuality have pointed to the manifold ways in which bisexuality is both erased and misrepresented (DuPlessis 1996; Yoshino 2000; Angelides 2001; MacDowall 2009). For instance, while female bisexuality has been particularly salient in popular culture (Johnson 2016), its authenticity has often been questioned, especially in cases where it is clear that such depictions have been construed for the gaze of heterosexual men (Johnson 2016). Questions of authenticity, however, have also been extended to the very idea of a bisexual identity, characterizing bisexuality as not having the same legitimacy as homosexuality and 
heterosexuality (DuPlessis 1996; Angelides 2001; MacDowall 2009). Angelides (2006:132) argues that this is because bisexuality has not been permitted the status of a legitimate sexual identity, as it would destabilize the 'epistemological integrity of the very categories of man, woman, heterosexual and homosexual'. This argument is congruent with one posited by Yoshino (2001) who explains that homosexual and heterosexual people are mutually invested in denying the visibility and existence of bisexuality and have conceded to an 'epistemic contract of bisexual erasure' in which bisexual people are not permitted the same ontological status as monosexual identities, i.e. homosexuality and heterosexuality.

While bisexual identity may have been repressed, bisexual practice has often been pathologized, having been represented as being responsible for transmission, infection, and - ultimately - scapegoated for the spread of HIV/AIDS to the heterosexual community (Kaestle and Ivory 2012). The ramifications of such discourses strengthened the notion that bisexual people were more promiscuous than the general population while also misrepresenting the methods through which the heterosexual population saw a rise in infection. In an article debunking the myth of the bisexual infector, Worth (2003:72) contended that not only were bisexual men 'deemed promiscuous, unreformable, dishonest fence sitters', but that their very identity had become conflated with HIV/AIDS meaning that they were now also perceived as 'dangerous'.

While the effects of bisexual erasure and misrepresentation are likely to be highly varied according to, inter alia, gender identity, 'race', ethnicity, class, ability, age, and region, Johnson (2016) demonstrates that bisexual people have worse health outcomes than the general population as well as when compared with the gay and 
lesbian population. Such outcomes are also manifest in higher rates of depression, mood anxiety disorders and higher rates of suicidality (Johnson 2016). Such outcomes are also attributed to the negative media representations which depict bisexual people as promiscuous, mentally unstable, lying about their sexuality, or performing their bisexuality for the consumption of others (Johnson 2016). In sum, 'poor media representation contributes to widespread biphobia, which contributes to poor mental health' (Johnson 2016).

The following section will describe how the current study addresses the preceding issues by building and analyzing a corpus of representative language concerning bisexuality.

\subsection{Methodology}

In order to map how bisexual people have been discursively constructed in The Times, I built a corpus that was a representative sample of language between 1957-2017. While using multiple publications would have provided for a broader perspective on how bisexuality has been represented across different publications, the decision was made to limit the study to a single newspaper, thus providing for a clearer focus on diachronic change. It was also important that the newspaper represented a centrist political ideology as a centrist political position is likely to reflect a middle-ground that is more representative of the social attitudes held by the majority of the British public. According to a YouGov poll (Smith 2017), the newspaper perceived as most representative of centrist politics is The Independent, however, as it has only been in circulation since 1986, The Times was chosen as the primary source of data. Although The Times was perceived as right-of-centre in the poll, it was the most centrist of the publications that fit the time period (see Figure 1). 


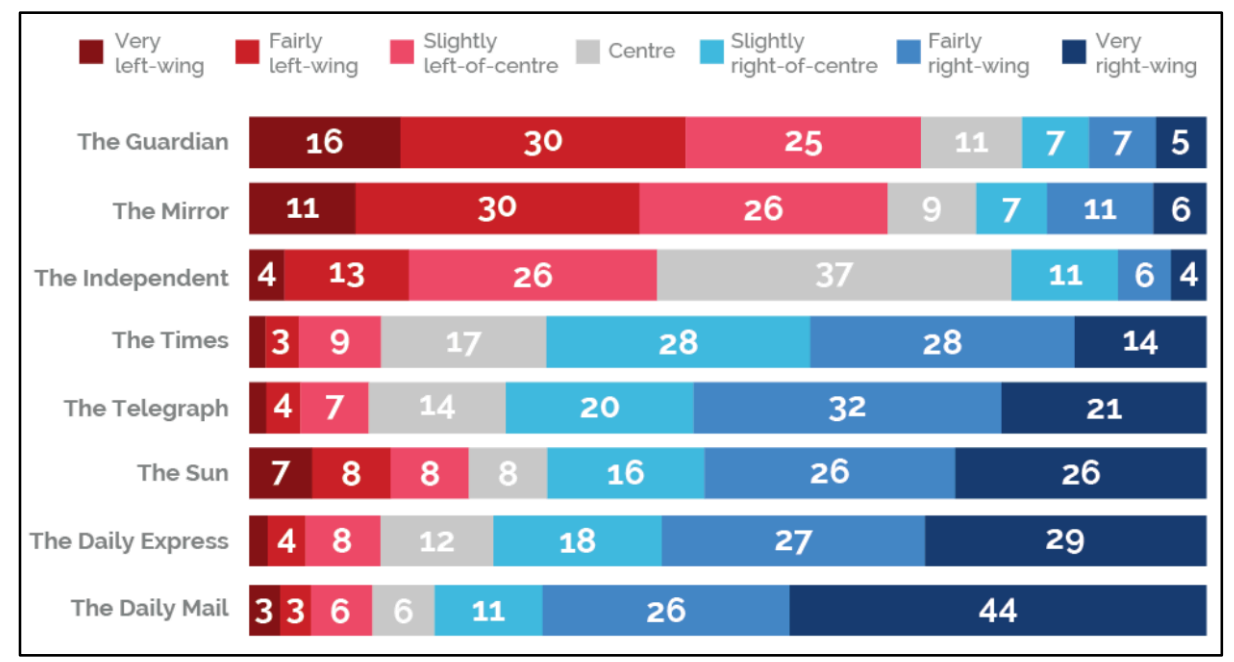

Figure 1: Public perceptions of newspaper ideology (Smith 2017)

Digital copies of The Times are available through The Times Digital Archive (TDA) which is an online database containing every issue published between 1785-2011. TDA is searchable by providing keywords as well as specifying time periods or publication sections. Results can be read online or downloaded as PDF files or Optical Character Recognition (OCR) texts. For the remaining dates, between 20112017, I used LexisNexis which also provides digital downloads of articles through a search of keywords and time periods.

In order to gain an insight into the diachronic shifts that occurred in bisexual representation, it was decided to search by date and select only the articles containing iterations of the lexeme bisexual that were published between 1957-2017. While the legal and social standing of bisexual people has been constantly evolving, these 60 years saw events in Britain that significantly impacted on their lived experiences. Such a broad time period, however, meant that the corpus contained significant differences in the quantity of data due to changes in both the quantity of news printed and the likelihood that bisexual people would be explicitly represented through 
language. In order to facilitate the analysis, it was therefore decided to divide the corpus into 5 sub-corpora that reflected different 'eras' in the history of bisexual people living in Britain. Table 1 provides an overview of the time periods, historical context, and the quantity of data for each of the 5 sub-corpora.

\begin{tabular}{|c|c|c|}
\hline Time period & Historical context & $\begin{array}{l}\text { Corpus size } \\
\text { (tokens) }\end{array}$ \\
\hline 1957-1967 & $\begin{array}{ll}\text { - } & \text { The Wolfenden Report } \\
\text { - } & \text { The Sexual Offences Act } 1967\end{array}$ & 11,755 \\
\hline 1968-1978 & $\begin{array}{ll}\text { - } & \text { The Sexual Revolution } \\
\text { - } & \text { The Lesbian and Gay Liberation Movement } \\
\end{array}$ & 65,294 \\
\hline $1979-1990$ & $\begin{array}{ll} & \text { Margaret Thatcher's premiership } \\
\text { - } & \text { The rise of the HIV/AIDS crisis } \\
\end{array}$ & 136,358 \\
\hline $1991-2003$ & $\begin{array}{l}\text { - Improved treatment for HIV/AIDS } \\
\text { - Adoption and immigration rights for same-sex } \\
\text { couples } \\
\text { - } \text { Repeal of Section } 28\end{array}$ & 705,601 \\
\hline $2004-2017$ & $\begin{array}{ll} & \text { Gender Recognition Act } 2004 \\
\text { - } & \text { Civil Partnership Act } 2004 \\
\text { - } & \text { (Same-sex) Marriage Act } 2013\end{array}$ & $2,872,512$ \\
\hline
\end{tabular}

Table 1: List of sub-corpora with time periods, historical context, and the quantity of

$$
\text { data }
$$

The 5 sub-corpora were then uploaded onto the online corpus analysis platform, Sketch Engine (Kilgariff et al. 2004). Like other corpus analysis tools, Sketch Engine allows users to store corpora on its database which is then used to generate information such as collocation, concordance lines, and word frequency. One useful tool is the 'Word Sketch' function which is 'an automatic corpus-derived summary of a word's grammatical and collocational behaviour' (Kilgariff et al. 2010:1) that is calculated using a logDice score (Rychlý, 2008). Baker et al. (2013:260) argue that the 'Word Sketch' function 'provides a more sophisticated picture of collocational patterns than merely considering pairs of words together'. Comparing 'Word Sketches' from different time periods in The Times corpus, therefore, provided insight 
into how the relationships between words convey cultural information which cumulatively - may be significant in how bisexuality is represented over time.

The 'Word Sketch' is categorized according to the grammatical function of the node word in context. These categories are:

- Modifiers of "bisexual"

- Modified by "bisexual”

- "Bisexual" and/or

- Prepositional phrases

- Verbs before "bisexual"

- Subjects of "be bisexual"

I began by looking for semantic patterns within each of the grammatical categories generated by the 'Word Sketch'. On the one hand, I took a 'naïve' approach by simply looking for similarities and differences in meaning that might indicate how the lexeme bisexual was being used. While this revealed unexpected patterns, I was also guided by the social problem of bisexual erasure or misrepresentation. I was therefore also looking for words that might indicate the extent to which The Times has contributed to these phenomena. While this approach was certainly beneficial for the larger corpora, a different approach to the data was required for the earlier decades.

Between 1957-1990, the corpora were not large enough to warrant generating a 'Word Sketch'. Instead, the data required a more qualitative approach and was instead analysed through a close reading of concordance lines. As noted by McEnery and Baker (2017b:214), smaller corpora often lead the researcher away from more quantitative approaches and back to a focus on individual texts. The following 
discussion will therefore begin with a qualitative analysis of concordance lines between 1957-1990. This qualitative analysis will then be compared with the patterns generated by the two 'Word Sketches' obtained from the sub-corpora between 19912017.

\subsection{Analysis}

\subsection{The Evolution of Bisexual - From Oysters to Space Stations}

Between 1957-1967, iterations of the lexeme bisexual only occurred 16 times, with a closer reading of the concordance lines revealing that only 5 out of the 16 occurrences of bisexual referred to an individual who is sexually or romantically attracted to both male and female identified individuals. The remaining 11 occurrences suggested that the meaning of bisexual has changed significantly. For instance, the corpus revealed that The Times more frequently used bisexual to refer to someone or something, e.g. oysters, that had both male and female reproductive organs and capabilities:

\begin{tabular}{|rll|}
\hline $\begin{array}{r}\text { his or her is correct, for the British oyster is } \\
\text { 250-150 million years ago, provide evidence of }\end{array}$ & bisexual & The American oysters, by the way, are males or females \\
found all the species that he has studied to be & bisexual. & They have a closed circulation system containing large
\end{tabular}

Concordance 1: Bisexual-organisms that are not sexually differentiated

Another unexpected use of bisexual was situations that involved both men and women. Two of the occurrences used the term to debate the possibility of a 'bisexual priesthood' in which women would could become ordained priests in the Church of England, while one other occurrence was used in reference to sports that could be played by both men and women (Concordance 2). 


$\begin{array}{rrl}\text { and they will become much more tangled with a } & \text { bisexual } & \text { official priesthood." Women and Holy Orders, Church } \\ \text { attached to the Report seem to fear that a } & \text { bisexual } & \text { priesthood could exacerbate personal jealousies } \\ \text { It is common experience that more individual and } & \text { bisexual } & \text { things like fencing, canoeing, and dancing tend to attract }\end{array}$

Concordance 2: Bisexual-comprising members of both male and female identified people

Mixed gender situations such as these were complemented by references to 'bisexual fragrances', a product that would now also likely be labelled 'unisex' as well as the 'bisexual nature' of certain instruments. Of the 5 occurrences that did refer to bisexuality as a sexual identity, two were ambiguous and could possibly have referred to someone who was androgynous in appearance and another whose 'bisexual nature' compelled them towards homosexuality, while yet another was used in a book review where the author describes how the letters sent by a male character to both a man and a woman were 'bisexual', but not the person who had written them (Concordance 3).

\begin{tabular}{|rrl}
\hline torment of the poet's life lay in his & bisexual & nature and the resultant homosexual \\
performance in the part, he makes Lussurioso a & bisexual & exquisite, more absurd than evil. \\
to dissuade him, and fill much of the novel with & bisexual & letters back home to boy friend and wife. But
\end{tabular}

Concordance 3: Bisexual - other uses

While such uses of bisexual would appear unusual in an issue of The Times today, they comport with meanings that were in use at the time and date back to the $18^{\text {th }}$ century. According to the Oxford English Dictionary (OED) (2018), the term bisexual is first attested in 1793 in reference to a flower that contained both male and female reproductive organs. Indeed, a significant number of entries for bisexual in the OED allude to 'hemaphroditism' (OED, 2018). Of the 8 entries for bisexual in the OED, only 3 denote sexual or romantic attraction to members of 'both sexes' - a usage that became significant in the early $20^{\text {th }}$ century (OED, 2018). In addition to entries on biology and physical characteristics, the remaining entries support some of the uses in 
the corpus, referring to situations 'involving or comprising individuals of both sexes' (OED, 2018:np), or items that are 'suitable for or applicable to both men and women' (OED, 2018:np). Further support for this range of usage is explored by Macdowall (2009) who delineates three different uses for the term that have been in use since the $19^{\text {th }}$ century. He claims that the first usage of bisexual refers to 'forms of life that are sexually undifferentiated or thought to exhibit characteristics of both sexes' (Macdowall 2009:4). Unlike this first definition which was rooted in evolutionary theory, the second category of bisexual was 'used to describe a combination of masculinity and femininity in an individual' (Macdowall, 2009:4). This second usage comports with contemporary notions of androgyny and first came into use in the early $20^{\text {th }}$ century. At around the same time, bisexual comes to signify sexual and romantic attraction to male and female identified individuals (Macdowall, 2009). Based on the evidence from the corpus and MacDowall (2009), the term bisexual can therefore be used to signify a combination of characteristics that are based on the binary oppositions of male/female, masculine/feminine, and heterosexual/homosexual. Evidence from the corpus, however, demonstrates that, while there is consistent semantic variation between $1957-1990$, it is bisexuality as a sexual identity that comes to dominate the language of The Times.

This shift in meaning becomes evident in the data between 1968 and 1978. During this time, the ratio of the lexeme bisexual to denote a sexual identity increases from $31 \%(1957-1967)$ to $66 \%$ just a decade later. The remaining cases fall roughly into the same categories discussed above, with the majority of usage referring to 'bisexual clothing and fashion' as well as people whom we would now likely characterize as 
intersex or transgender ${ }^{2}$. In addition to these examples, there are also 2 concordance lines that contain a disambiguation of 'androgynous' through the use of 'bisexual' in parentheses (Concordance 4). In the first concordance line, the author is referring to the dock of a space station which is 'androgynous', while in the second, the author refers to the potential androgyny of the Judaeo-Christian god. The use of bisexual to disambiguate androgynous is interesting because it suggests that bisexual was falling out of common use and being replaced by terms that are more familiar by contemporary standards. While there are only two examples of bisexual being used to clarify a word that had come to replace it, the decreasing frequency with which bisexual was being used to signify intersex, transgender, androgynous or unisex is evidenced further in the next section of the corpus.

draw up preliminary plans for a so-called androgynous ( bisexual ) system "that is neither male nor female in design"

"he". Biblical images of a female or an androgynous (i.e. bisexual ) deity put forward by Dr Morton included the pillar of

Concordance 4: Bisexual as disambiguation for androgynous

\subsection{The Roots of Bisexual Erasure - HIV/AIDS and Conflation Through Inclusion}

Between 1979-1990, the use of bisexual to refer strictly to a sexual identity grew from $66 \%$ to $92 \%$. This demonstrates that, during this era, bisexual largely ceased being used in the female/male and feminine/masculine paradigms and came to almost exclusively represent a third space in the homosexual/heterosexual binary. While there are likely to be other factors involved in this shifting lexical meaning, there is

\footnotetext{
2 It is important to note that the meanings signified in terms such as 'transgender' and 'intersex' - as well as the language itself - are historically contingent and cannot therefore be read backwards in time as universal terms that would have signified the same thing in the 1960s and 1970s. They are instead used as familiar terms - or shorthand - to highlight how the meaning signified in the word bisexual has shifted over the time period in question.
} 
considerable evidence that, during the 1980s, the HIV/AIDS crisis played a significant role in how bisexuality figured in the discourse of The Times. After removing non-contemporary uses of bisexual and controlling for duplicates, there were a remaining 227 tokens of the lexeme bisexual. Of these, $52 \%$ were used in the discussion of HIV/AIDS.

An examination of the concordance lines shows that bisexual people were represented in two distinct, but not always discrete ways. First, bisexual people tended to be folded into discursive groupings with other 'high-risk groups' (Concordance 5). The corpus presents examples in which bisexual people would be listed with people described in the corpus as 'homosexuals... intravenous drug users, haemophiliacs', 'prostitutes', and 'the very promiscuous'. Aside from haemophiliacs, these groups of individuals were not only described as having higher rates of infection, but were also presented as culpable for their HIV status as well as the growing epidemic.

\begin{tabular}{|c|c|c|}
\hline $\begin{array}{l}\text { the great majority are male homosexuals or } \\
\text { at risk include practising homosexuals, }\end{array}$ & $\begin{array}{l}\text { bisexuals } \\
\text { bisexuals }\end{array}$ & $\begin{array}{l}\text {, or injecting drug misusers, but in about } 5 \\
\text { intravenous drug addicts, haemophiliacs }\end{array}$ \\
\hline men with the disease, 1,226 are homosexual or & bisexual & ; 85 haemophiliacs; 43 intravenous drug \\
\hline used to treat their condition. Homosexuals, & bisexuals & and intravenous drug abusers continue to \\
\hline the main risk groups were still homosexuals, & bisexuals & and drug addicts. The figures showed that of \\
\hline
\end{tabular}

Concordance 5: bisexual people with other 'high-risk groups'

While, bisexual people existed in the same discursive environment as other 'high-risk groups', it was with homosexuals that they were most closely aligned. In fact, 55\% of the bisexual tokens returned in the search were paired with homosexual through the use of conjunctions such as and, or and the symbol, ' $\%$. The frequency of such usage suggests that, for the first time, bisexual consistently collocates with homosexual and, in effect, contributes to the notion of bisexual erasure (Angelides 2001). In other words, as bisexual becomes folded into a discursive category with homosexual, 
bisexuality as a distinct identity and group becomes compromised and, indeed, conflated with homosexuality more broadly.

\begin{tabular}{|c|c|c|}
\hline sneeze. It seems that the semen of infectious & bisexual & men could be a danger to female partners. \\
\hline be as well to avoid intercourse with a & bisexual & or the very promiscuous. $09.28 .85 \mathrm{As}$ \\
\hline presumably being transmitted to women by & bisexual & men. There is some concern that prostitutes \\
\hline are believed to have caught the virus from & bisexual & or drug abusing men. "The increasing \\
\hline to know, the truth about their partner's & bisexuality & , or past history of drug-taking. As one New \\
\hline active women, especially those who have & bisexual & partners, to avoid becoming pregnant. In a \\
\hline envisions New York after Aids has become a & bisexual & plague; Talk Radio (Public Theatre) exposes \\
\hline discovered that she had contracted Aids from a & bisexual & lover some years previously. Her husband man \\
\hline contracted Aids after a one-night stand with a & bisexual & . A teenager who thought it could not happen to \\
\hline exposure to the virus was sexual contact with a & bisexual & . Britain may have 1,800 new Aids patients in \\
\hline
\end{tabular}

Concordance 6: Bisexual people represented as a 'bridge' for HIV infection

In the 33 years between 1957-1990, the term bisexual came to signify something very different from whence it had begun. It had transitioned from having various meanings to primarily signifying a fixed sexual identity at the margins of society. This marginal nature meant that, in their vulnerability to the HIV/AIDS crisis, they became discursively represented as the bridge between deviant populations associated with the epidemic and the broader heterosexual population. Discourses of a discrete bisexual sexual identity could therefore be argued to have both contributed to their formation as a discrete identity category associated with sexual practice, while simultaneously contributing to their erasure within the broader homosexual community.

\subsection{Fictional and Temporal Displacement of Bisexuality}

While the previous 3 sub-corpora have demonstrated how the term bisexual changed significantly between 1957-1990, there was one way in which bisexual representation remained consistent, and indeed, has continued to be until 2017. Namely, The Times 
has consistently represented bisexuality in discourses of fiction and the past. One of the ways in which this fictional and temporal displacement of bisexual people is made evident is through their ubiquity in the 'Reviews' section of The Times. The TDA divides articles into 8 sections and 25 sub-sections including subject areas such as 'Reviews', 'News', and 'Editorials/Leaders'. While one might expect bisexuality to be featured in several sections, bisexual people are overwhelmingly featured in the 'Reviews' section and, largely, as characters in theatre productions, film, and television (Table 2). Between 1957-1967, the lexeme bisexual occurred in the 'Reviews' section $50 \%$ of the time. Between 1968-1978, this percentage dropped to $42 \%$ and then, as a result of bisexuality and HIV/AIDS discourses, it fell further to $22 \%$ between 1979-1990 as bisexual became largely featured in the 'News', which now comprised $42 \%$ of its mentions.

\begin{tabular}{|l|l|l|l|l|}
\hline & \multicolumn{5}{|l|}{ SECTIONS IN THE TIMES } \\
\hline Years & Reviews & News & Arts \& Entertainment & Other \\
\hline $1957-1967$ & $50 \%$ & $38 \%$ & $0 \%$ & $12 \%$ \\
\hline $1968-1978$ & $54 \%$ & $23 \%$ & $4 \%$ & $18 \%$ \\
\hline $1979-1990$ & $24 \%$ & $42 \%$ & $20 \%$ & $14 \%$ \\
\hline $1991-2003$ & $31 \%$ & $21 \%$ & $21 \%$ & $30 \%$ \\
\hline $2004-2017$ & N/A & N/A & N/A & N/A \\
\hline
\end{tabular}

Table 2: Distribution of bisexual by publication section

Nevertheless, while the language of bisexuality eventually moved out of the 'Reviews' section of the The Times, discourses surrounding bisexuality continued to be relegated to the realm of fiction and of the past. That is to say that, if bisexuality was discussed in reality, it was either referred to as a sexual practice that had occurred in someone's life but no longer did at the time of writing - e.g. ' If I ever have grandchildren, I'll probably make them listen to stories about when I was bisexual '; an ongoing practice in someone's life who was no longer living - e.g. 'Michael 
Redgrave was a bisexual and an alcoholic'; or in the far distant past - e.g. '(Julius) Caesar himself was bisexual'.

This fictional and temporal displacement of bisexual individuals continues to be salient in the sub-corpora dating between 1991-2003 and 2004-2017. Due to the size of these sub-corpora, the 'Word Sketch' function was used to identify collocates that would likely indicate how bisexuality was being represented in The Times. The 19912003 corpus returned 56 types and 540 tokens that collocated with bisexual. Through a close reading of the concordance lines in each of these groupings, it became evident that bisexual was frequently used in discourses that dealt with the past or in fiction.

An analysis of words that were "modifiers of "bisexual" showed that $67 \%$ of the examples discussed bisexuality and bisexual individuals within discourses of the past. These included the ancient Gaels who were described as 'partly bisexual', Leonardo Da Vinci who was 'almost certainly bisexual', and Lord Byron's half-sister, Augusta, who was 'probably bisexual herself' (alluding to Lord Byron's sexuality as well). On the other hand, while past was one of the highest frequency collocates in the 'modified by "bisexual"' section of the 'Word Sketch' (Figure 2), discourses dealing with fiction were more significant than discourses of the past. For instance, writers at The Times frequently discussed 'bisexual girlfriends', 'bisexual love triangles' and, of course, 'bisexual characters' all within films, television, and theatre. Beyond such bisexual tropes as 'triangle', however, fictional bisexual characters also included bisexual 'barrister(s)', 'queen(s)', and two instances of a bisexual 'cameraman'. In fact, $46 \%$ of the collocates that were modified by bisexual were used in the discussion of fiction, a ratio that was followed by discourses of HIV/AIDS at $19 \%$ and the past at $15 \%$. 


\begin{tabular}{|lll|}
\hline nouns and verbs modified by & "bisexual" \\
\hline man & $\underline{37}$ & 10.38 \\
\multicolumn{1}{|c}{ bisexual men } & & \\
girlfriend & $\underline{5}$ & 9.07 \\
star & $\underline{6}$ & 8.60 \\
lover & $\underline{4}$ & 8.54 \\
artist & $\underline{4}$ & 8.47 \\
cameraman & $\underline{3}$ & 8.45 \\
designer & $\underline{3}$ & 8.40 \\
past & $\underline{3}$ & 8.38 \\
triangle & $\underline{3}$ & 8.33 \\
queen & $\underline{3}$ & 8.28 \\
singer & $\underline{3}$ & 8.22 \\
partner & $\underline{3}$ & 8.22 \\
woman & $\underline{5}$ & 8.19 \\
hero & $\underline{3}$ & 8.18 \\
character & $\underline{3}$ & 7.97 \\
relationship & $\underline{3}$ & 7.88 \\
philanderer & $\underline{2}$ & 7.86 \\
libertine & $\underline{2}$ & 7.86 \\
dentist & $\underline{2}$ & 7.86 \\
dwarf & $\underline{2}$ & 7.85 \\
statue & $\underline{2}$ & 7.83 \\
sam & & 7.83 \\
barrister & & 7.82 \\
liaison & & 7.81 \\
dancer & & 7.78 \\
\hline
\end{tabular}

Figure 2: Nouns and verbs modified by "bisexual" (1991-2003)

This trend was complemented by the grouping, "verbs before "bisexual", which showed that the lemma be was the most significant collocate of bisexual. Of the 79 tokens, 42 used 'was' or 'were' to discuss someone's bisexual past or a bisexual person who lived in the past. In fact, the only grouping that revealed a slightly different story were collocates that were connected through the conjunctions 'and/or' (Figure 3). There were still numerous examples of fictionalized bisexual people, including 'black, bisexual warrior(s)' and 'dwar(ves)', 'boozy, bisexual mother(s)' and 'aunt(s)', and a 'feisty, bisexual loner'. The majority of collocates, however, folded bisexual within discourses concerning homosexuals and gay people - a discursive strategy that conflates the unique identity of bisexual people with the larger community of (in this corpus) mostly homosexual and gay men. 


\begin{tabular}{|c|c|c|}
\hline \multicolumn{3}{|c|}{ "bisexual" and/or ... } \\
\hline \multicolumn{3}{|c|}{36.30} \\
\hline gay & $\underline{44}$ & 11.76 \\
\hline \multicolumn{3}{|c|}{ gay or bisexual } \\
\hline homosexual & $\underline{26}$ & 11.64 \\
\hline \multicolumn{3}{|c|}{ homosexual or bisexual } \\
\hline lesbian & $\underline{12}$ & 10.41 \\
\hline heterosexual & $\underline{4}$ & 9.23 \\
\hline black & $\underline{4}$ & 9.00 \\
\hline androgynous & $\underline{3}$ & 8.94 \\
\hline straight & $\underline{3}$ & 8.83 \\
\hline unbalanced & $\underline{2}$ & 8.36 \\
\hline transgendered & $\underline{2}$ & 8.36 \\
\hline boozy & $\underline{2}$ & 8.35 \\
\hline feisty & $\underline{2}$ & 8.35 \\
\hline alcoholic & $\underline{2}$ & 8.35 \\
\hline hiv-positive & $\underline{2}$ & 8.35 \\
\hline giant & $\underline{2}$ & 8.35 \\
\hline middle-aged & $\underline{2}$ & 8.34 \\
\hline pop & $\underline{2}$ & 8.33 \\
\hline young & $\underline{3}$ & 8.30 \\
\hline famous & $\underline{2}$ & 8.28 \\
\hline beautiful & $\underline{2}$ & 8.19 \\
\hline american & $\underline{2}$ & 7.97 \\
\hline sexual & $\underline{2}$ & 7.73 \\
\hline
\end{tabular}

Figure 3: "bisexual" and/or (1991-2003)

The 2004-2017 corpus further supports this observation, demonstrating how bisexual has increasingly become locked in as one component in the broader LGBTQ community. In a 'Word Sketch' of bisexual, $50 \%$ of the 2064 collocates demonstrated that bisexual collocates primarily with lesbian, gay, transgender, queer and intersex, thus becoming simply one letter in the abbreviated community labels $L G B, L G B T$, or $L G B T Q I$. Such erasure through inclusion/conflation was further demonstrated as another 124 examples of bisexual were incorporated within the language of men's sexual identities and practices more broadly, e.g. 'gay and bisexual men' or 'homosexual or bisexual men' (Figure 4). 


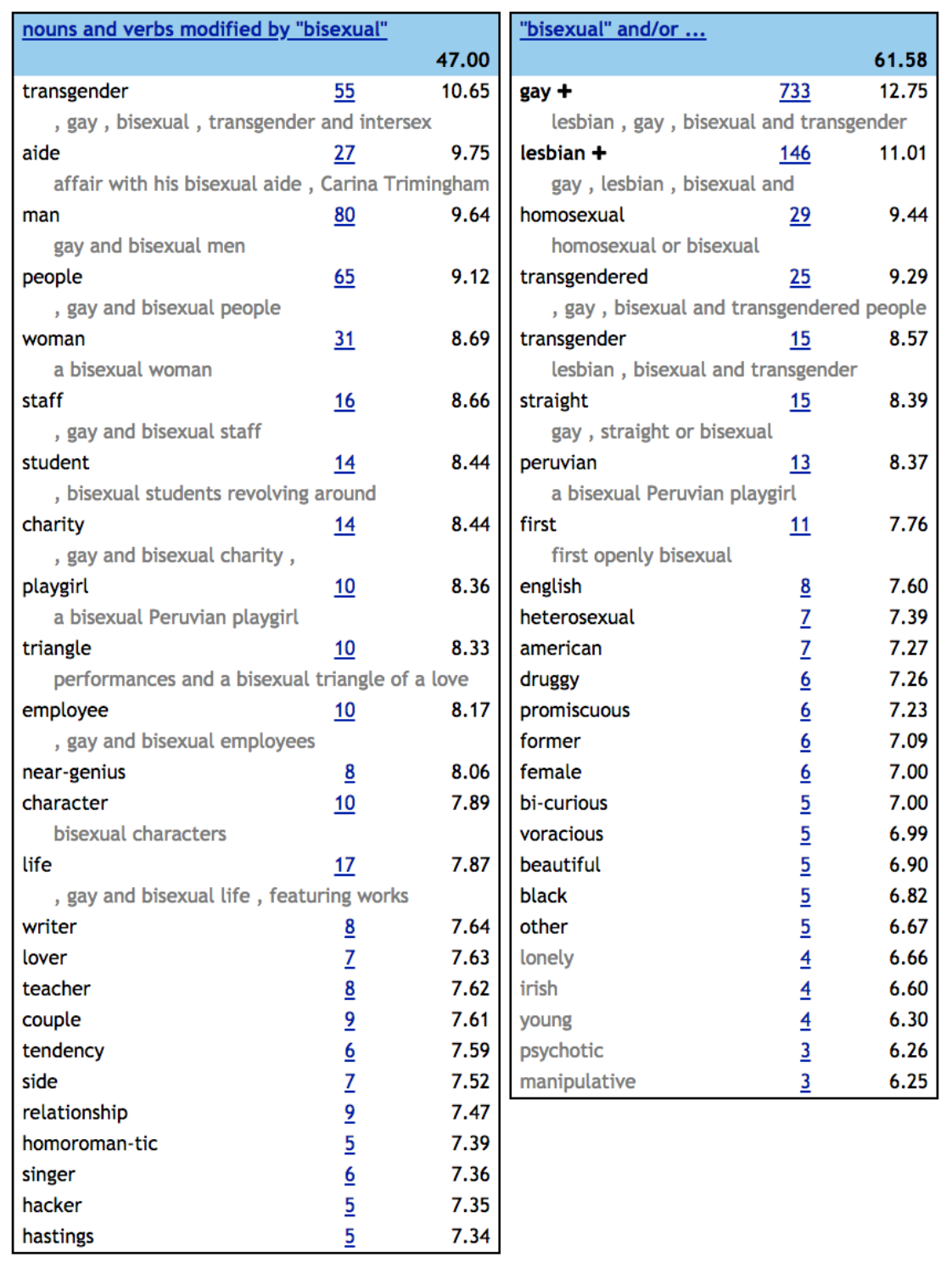

Figure 4: 'Nouns and verbs modified by bisexual' and 'bisexual and/or' (2004-2017)

Where bisexuality was discussed as an identity or practice in its own right, it continued to be relegated to fictional discourses and the historical past tense. An analysis of words that modified bisexual revealed how $41 \%$ were used to describe people who had lived in the past or who had practiced bisexuality in the past, but no longer did. These examples also used words that suggested skepticism, as the articles seemed to question whether their subjects were 'possibly bisexual', 'perhaps bisexual' or 'probably bisexual'. This suggests that, in The Times, bisexuality is rarely 
accepted as a fact of one's identity, but is rather a suspicion of past actions that are open to question and subject to scrutiny (Concordance 7).

$\begin{array}{ccc}\text { are Georgiana, the gambling-addicted, possibly } & \text { bisexual } & 18^{\text {th }} \text {-century duchess and the early Victorian duke who } \\ \text { whether MacMillan was homosexual, or perhaps } & \text { bisexual } & \text { There is some suggestion that he might have been } \\ \text { a morbid, sadomasochistic psychopath, probably } & \text { bisexual } & \text { who employed young men to flog him and slept with }\end{array}$

Concordance 7: Skepticism of bisexuality

Examples such as 'flamboyantly bisexual' - also in the "modifiers of "bisexual"" category - also indicate a level of judgment when considering bisexual identity. A Word Sketch of flamboyant and flamboyantly in the British National Corpus (BNC) reveal that their subjects are often negative and would therefore benefit from being less flamboyant and more covert, such as flamboyant 'voyeurs', 'exhibitionists', 'charlatans' and 'homosexual(s)'. This negative discourse prosody would also suggest that one's bisexuality is something that ought to be kept secret as a source of shame and certainly not to be displayed 'flamboyantly'. Such negative representations of bisexual people were echoed in fictional discourses as well. There were certainly associations with bisexual that appeared neutral, such as 'teachers', 'writers' and 'characters' but, echoing the evaluative discourses in the 1980s, there continued to be collocates which suggested the inherent promiscuity and depravity associated with bisexual people (Johnson 2016). In the 'Word Sketch' grouping that shows collocates connected to bisexual through and/or, 'voracious', 'promiscuous', 'manipulative' and 'psychotic' were all notable suggesting that bisexual people, if represented as such, are likely to be perceived as such as well.

\subsection{Conclusion}

The preceding analysis of how bisexuality was represented in The Times corpus both confirms and complicates the notion of bisexual erasure and the idea that bisexual 
people are misrepresented in the language of the British Press. In the 'Word Sketch' analysis, bisexuality - when discussed independently of other sexual identities - is rarely discussed in the present tense - a finding is congruent with many contemporary critiques of bisexual representation (DuPlessis 1996). In addition to temporal displacement, the corpus demonstrated that, where bisexual people are located in temporally proximate spaces, they tend to be relegated to the world of fiction.

This is significant because, where temporal displacement largely became salient after 1991, fictional displacement was salient throughout the entire 60 years of data. The process of fictionalising a minority group is important for two reasons. First, while representation is arguably positive for minority groups, questions of how groups are represented and, indeed why they are represented, are also crucial. hooks (1992:170) challenges the idea that fictional representation is generally beneficial as fictions, like stereotypes, are 'created to serve as substitutions, standing in for what is real'. Furthermore, when we deal with negative representation, the very fact that it is fiction or that it is dealing in the past means that those who are claimed to be represented are not here to defend themselves. The result is that such representations may become legitimated through a lack of opposition. Finally, fictionalisation implies that bisexual people simply do not exist as social actors in reality, thereby exacerbating bisexual erasure by contributing to the effects of temporal displacement.

Paradoxically, bisexuality was further suppressed through the very process of representation. In the later years of the corpus, umbrella terms such as 'LGBT' began to fold bisexuality within broader notions of a so-called 'LGBT community'. While potentially beneficial, such inclusion can actually manifest in conflation, thereby obfuscating the unique position of bisexual people both in terms of their identity and, 
by extension, the various challenges that are unique to bisexual people. Such inclusion through conflation can actually be traced back to the HIV/AIDS crisis, when bisexual first began to frequently occur next to the term homosexual. Represented not only as victims of the HIV/AIDS, 'homosexuals and bisexuals' also became identified with the virus itself. This has had a lasting effect on how the bisexual population are represented in the language of The Times as notions of promiscuity, deviance and risk continue to be associated with bisexual people up until the present day.

Corpus-based critical discourse analysis assumes that the way phenomena are frequently represented through language impacts on how they are perceived (Stubbs 1996, 2001). This poses a problem though when asking questions about representation in smaller quantities of data. Between 1957-1990, the corpora were too small to even justify using tools like collocation and frequency calculations. A return to close reading of concordance lines proved more fruitful, revealing how the semantic meaning of bisexual developed from a word with varied meanings to one that almost exclusively signified a sexual identity. This is significant because it shows how language - especially in terms of identity - is historically and culturally contingent. While the lack of data makes it difficult to draw conclusions about how bisexuality was represented and likely perceived, the data that is available suggests that identifying with bisexuality as a sexual identity would have been unlikely. In other words, if the language of bisexual identity was not common at the time, then we can assume that people who were attracted to both male and female identified persons would not have seen themselves as bisexual. Finally, it is interesting to consider, however, that a bisexual identity may have become discursively realised through language in the mid- $20^{\text {th }}$ century before becoming suppressed through language just a few decades later. 
Discourses of sexual identity have changed significantly and, as was demonstrated in the analysis of bisexual, the language of identification can change considerably in a short period of time. New identificatory categories continue to emerge that contest and respond to our changing notions of gender and sexuality in contemporary Britain. Labels such as 'genderqueer', 'non-binary', and 'demi-sexual' are all present in the more recent language use of The Times. Most frequent though is the term pansexual which refers to people who are 'not limited or inhibited in sexual choice with regards to gender or practice' (OED 2018:np). In a search of The Times between 1957-2017, pansexual occurred 99 times - the majority of these occurring since 2007. In a new linguistic landscape that has opened-up and deconstructed the gender binary, the term bisexual again finds itself in a tenuous position. Namely, if bisexuality is perceived as upholding the gender binary, it is possible that its colloquial use may become less popular among those who no longer subscribe to the binary gender paradigm. On the other hand, bisexual people may increasingly redefine their sexuality, emphasizing that their sexual identity falls within a group of 'plurisexual' identities whose objects of attraction are extended beyond the bi- in binary to any number of gender identities (Paz Galupo et al. 2017). Based on the evidence from 60 years of corpus data, however, it seems certain that, as contemporary discourses of gender and sexuality shift, so too will the term bisexual as will the historically and culturally contingent identity of bisexual people. 


\section{REFERENCES}

Angelides, S. (2001) A History of Bisexuality. Chicago: University of Chicago Press.

Angelides, S. (2006) 'Historicizing (Bi)Sexuality', Journal of Homosexuality 52(1-2):125158

Baker, P. (2005) Public Discourses of Gay Men. London: Routledge.

Baker, P. (2010) Sociolinguistics and Corpus Linguistics. Edinburgh: Edinburgh University Press

Baker, P. (2014) Using Corpora to Analyze Gender. London: Bloomsbury

Baker, P., Gabrielatos, C., Khosravinik, M., Krzyżanowski, M., McEnery, T. and Wodak, R. (2008) 'A Useful Methodological Synergy? Combining Critical Discourse Analysis and Corpus Linguistics to Examine Discourses of Refugees and Asylum Seekers in the UK Press', Discourse and Society 19(3): 273-306.

Baker, P., Gabrielatos, C. and McEnery, T. (2012) 'Sketching Muslims: A Corpus Driven Analysis of Representations Around the Word 'Muslim' In The British Press 1998-2009', Applied Linguistics 34(3): 255-278.

Baker, P., Gabrielatos, C. And Mcenery, T. (2013) Discourse Analysis and Media Attitudes: The Representation of Islam in the British Press. Cambridge: Cambridge University Press

Butler, J. (1991) Gender Trouble. Feminism and the Subversion of Identity. New York: Routledge

Cook, M., Mills, R., Trumbach, R. and Cocks, H., (2007). A Gay History of Britain: Love and Sex Between Men Since the Middle Ages. Oxford: Greenwood World Publishing

Du Plessis, M. (1996) Blatantly Bisexual; or, Unthinking Queer Theory. In Pramaggiore, M. and Hall, D.E. (eds) (1996) Representing Bisexualities: Subjects and Cultures of Fluid Desire. New York: NYU Press

Fairclough, N. (1989) Language and Power. London: Longman

Foucault, M. (1972) The Archaeology of Knowledge. London: Tavistock Publications.

Foucault, M. (1978) The Will to Knowledge: The History of Sexuality Volume 1. London: Penguin Books

hooks, b. (1992) Black Looks: Race and Representation. Boston: South End Press

Johnson, H. (2016) 'Bisexuality, Mental Health, and Media Representation', Journal of Bisexuality, 16(3): 378-396 
Kaestle, C. and Ivory, A. (2012) 'A Forgotten Sexuality: Content Analysis of Bisexuality in the Medical Literature Over Two Decades', Journal of Bisexuality 12(1): 35-48.

Kilgariff A., Kilgarriff, V., Bušta, J., Jakubíček, M., Kovář, V., Michelfeit, J., Rychlý, P. and Suchomel, V. (2014) 'The Sketch Engine: Ten Years On', Lexicography 1:7-36

MacDowall, L. (2009) 'Historicising Contemporary Bisexuality', Journal of Bisexuality 9(1): 3-15

McEnery, T. and Baker, H. (2017a). Corpus Linguistics and 17th-Century Prostitution: Computational Linguistics and History. London: Bloomsbury Academic

McEnery, T. and Baker, H. (2017b) 'The Public Representation of Homosexual Men in Seventeenth-Century England - A Corpus Based View', Journal of Historical Sociolinguistics 3(2): 197-217

Oxford English Dictionary (Online) $3^{\text {rd }}$ Edition (2018) s.v. Bisexual. (Accessed on 14/04/2018) Available from: http://www.oed.com/view/Entry/19448\#eid19689043

Oxford English Dictionary (Online) $3^{\text {rd }}$ Edition (2018) s.v. Pansexual. (Accessed on 14/04/2018) Available from:

http://www.oed.com/view/Entry/136944?redirectedFrom=pansexual\#eid

Partington, A., Duguid, A., and Taylor, C. (2013) Patterns And Meanings In Discourse: Theory and Practice in Corpus-Assisted Discourse Studies (CADS). Amsterdam: John Benjamins Publishing Company

Paz Galupo, M., Ramirez, J. and Pulice-Farrow, L. (2017) “"Regardless of Their Gender”: Descriptions of Sexual Identity among Bisexual, Pansexual, and Queer Identified Individuals', Journal of Bisexuality, 17(1):108-124

Rychlý, P. A Lexicographer-Friendly Association Score. Proc. 2nd Workshop on Recent Advances in Slavonic Natural Languages Processing, RASLAN 2: 6-9

Smith, M. (2017). 'How Left or Right Wing are UK Newspapers?', YouGov. (Accessed 01/05/2018) Available from: https://yougov.co.uk/news/2017/03/07/how-left-or-right-wingare-uks-newspapers/

Stubbs, M. (1996) Text and Corpus Analysis: Computer-assisted Studies of Language and Culture. Oxford: Blackwell Publishers

Stubbs, M. (2001) Words And Phrases: Corpus Studies of Lexical Semantics. Oxford: Blackwell Publishers

Sunderland, J. (2004) Gendered Discourses. Basingstoke: Palgrave Macmillan.

Van Dijk, T. (1993) Principles of Critical Discourse Analysis. Discourse and Society, 4(2), pp.249-283. 
Weeks, J. (2016) Coming Out: The Emergence of LGBT Identities in Britain from the $19^{\text {th }}$ Century to the Present. London: Quartet Books.

Worth, H. (2003) 'The Myth of the Bisexual Infector?', Journal of Bisexuality 3(2): 69-88

Yoshino, K. (2001) The Epistemic Contract of Bisexual Erasure. Stanford Law Review.

52(2): 353-461 